\title{
Parametric Study of Thermal Characterization of Nano Drilling Fluid
}

\author{
Hossein Khaje Esfandiary ${ }^{1}$, Farshad Farahbod ${ }^{2, *}$ \\ ${ }^{1}$ Department of Petroleum Engineering, Omidieh Branch, Islamic Azad University, Omidieh, Iran \\ ${ }^{2}$ Department of Chemical Engineering, Firoozabad Branch, Islamic Azad University, Firoozabad, Iran \\ Email address: \\ esfandiary@yahoo.com (H. K. Esfandiary),f.farahbod@iauf.ac.ir (F. Farahbod) \\ ${ }^{*}$ Corresponding author
}

\section{To cite this article:}

Hossein Khaje Esfandiary, Farshad Farahbod. Parametric Study of Thermal Characterization of Nano Drilling Fluid. Fluid Mechanics. Vol. 3, No. 1, 2017, pp. 1-5. doi: 10.11648/j.fm.20170301.11

Received: October 30, 2016; Accepted: November 9, 2016; Published: January 24, 2017

\begin{abstract}
Experiments are held to investigate the effect of ferric oxide nano particles on the thermo electrical properties of drilling slurry. The main purpose of this study is to improve the the thermo electrical properties of drilling slurry by nano ferric oxide. The objective of designing drilling fluid for extreme and deep environment (HPHT wells) is to develop high performance drilling fluid system in well bore to achieve zonal isolation. The primary objective of drilling fluid is to improve thermo electrical and rheological properties and displacement efficiency of drilling fluid system. Oil well slurries depend on its homogeneity of additive concentrations, quality and quantity to contribute the placement and success of a well drilling cementing operation. The experimental results prove that the ferric oxide nano particle as metal oxide nano particle can increase the thermal conductivity values, severely. Results show the behavior of nano drilling fluid in the conduction mechanism can followed by polynomial with order 3 th.
\end{abstract}

Keywords: Electrical Conductivity, Thermal Conductivity, Drilling Fluid Additives, High Performance Drilling Fluid System, Rheology, Ferric Oxide Nano Particle

\section{Introduction}

\subsection{Duty of Drilling Fluid}

During a well cementing operation purpose should be achieve zonal isolation (Nediljka et al., 1994). That belongs to the slurry design, to ensure the best quality of cementing especially at high temperature environment such a HPDFS Silica Fume (SF) use as a cement slurry additive to reduce the density of cement (Siddique and Khan, 2011). SF increase slurry performance and control hydrostatic pressure during drilling cementing. This mixture used as primary source for a hydraulic seal in the well bore as secondary application is used for remedial operations including depleted zone closing, splits and leaks repair (Nediljka et al., 1994). The function of SF is allows a well to reach full production potential besides producing a blocking effect in the oil well. It is also responsible to prevent gas migration and highly effective for proper placement and decrease permeability for better control of weak zones (Siddique and Khan, 2011).
Compressive strength of concrete containing SF is proved higher strength; as increase the concentration of silica fume it improves stress resistance in the early development and reduces the free water (Mehta and Gjorve, 1982). The mixing of silica fume into cement several optimum conditions are noticed (Shadizadeh et al., 2010):

- It is nature to consume more water to prove as $\mathrm{s}$ function of extender and substitute for lightweight cements.

- High water adsorption to increased pozzolanic reactivity promotes enhanced compressive strengths.

- The purity and solubility of the material makes it suitable for combating strength retrogression in cements at temperatures above $230^{\circ} \mathrm{F}\left(110^{\circ} \mathrm{C}\right)$.

\subsection{History and Literature Review}

Thermo electric and also, the rheological properties of drilling fluid play important role to determine the workability of slurry, fineness (Shahriar and Nehdi, 2012). The mixing process is very important parameters for thermal and 
rheological behavior of drilling slurry, the criteria of designing slurry depends on formulation, thermal conductivity, density, plastic viscosity, shears tress, yield point and gel strength for enhance durability and toughness for drilling slurry (Shahriar and Nehdi, 2011) Cement grout is used for sealing geothermal wells for is olatezones drilling fluid operation. The electrical and rheological behaviors of drilling slurry are important for the drilling process; it will be optimum to predict correctly about slurry placement (Bannister, 1980). Drilling slurry is concentrated suspensions of small and heavy particles so thermal and rheological measurements are suffering to the disruption of drilling operation (Miranda et al., 2010). The thermo electrical properties and the rheology of Oil Well drilling fluid (OWDF) should be considered when it applied on the originally and primarily casing drilling. Therefore, fundamental knowledge of OWDF slurry rheology is necessary to evaluate the ability to mix and pump grout, remove mud and slurry placement optimization and to predict the effect of temperature on the slurry pit (Shahriar and Nehd, 2011). Incomplete mud removal can result in poor drilling fluid bonding, zone communication and ineffective stimulation treatment (Bannister, 1980). A rheology is study related to the flow of fluids and deformation of solids under stress and strain. In shear flows, fictitious parallel layers of liquid past each other in response to a shear stress to produce a velocity gradient, in term of to shear rate, which is equivalent to the rate of increase of shear strain (Guillot, 2006). The property of drilling slurry is complex which has the appearance and interactions between the additives (Banfill and Kitching, 1991). The chemical composition of drilling fluid, particle distribution, test in $\mathrm{g}$ methods, size shape, W/DF ratio, mixing time and temperature (Frittella et $a l ., 2009)$. The drilling slurry is viscous plastic materials that exhibit yield stress and tension below the yield stress ultimately slurry behaves as a rigid and solid (Mirza et al., 2002). The Bingham plastic and power-law model is widely used to describe the rheological properties of drilling slurry measurements. Frittella et al. (2009) that can be determined the properties of drilling fluid flow i.e., plastic is cosity, yield point, friction characteristics and gel strength (Harris and Service, 1991). The concentration and form of so lid particles has a significant impact on the thermo electrical rheological properties of the OWDF slurry to yield stress and plastic viscosity of drilling paste usually increase as the cement becomes finer and increases the stability of slurry (Boukhelifa et al., 2004). Equivalent Circulating Density (ECD) is important factor to understand the flow behavior, flow rate, annular velocity and differential pressure; for that purpose number of computer simulation software is available to predict the ECD. The displacement efficiency is achieving the maximum mud displacement. A standoff value of the percentage of casing centralization in the wellbore, job operation time for proper thickening and Reynolds numbers base on laboratory methods is measuring rheological properties to understand flow behaviors (Labibzadeh et al., 2010). These parameters will be evaluating the drilling fluid pump-ability and drilling paste grout with strength correspond to behind the casing to increase efficiency and displacement. High flow rate may cause fracture the formation there should be investigated the current effective equivalent cement density (Hodne, 2007). The maximum drilling fluid or colloids or emulsions as a non-Newtonian liquids in plastic or behave in such circumstances is that the gel analysis function of the intermolecular forces. The initial 10 -sec and 10-min gel strength measurements gelation indications of the gel that will occur after the flow is stopped and the drilling fluid remain static (Teodoriu et al., 2008). When circulating drilling mud and fluids during cementing operations abnormal results in bottom hole, which may cause challenge to the integrity and safety. Soliman et al. (2008). To maintain hydrostatic pressure of the fluid column below the fracture gradient but above the pore pressure and designing drilling slurry to improve efficiency and displacement without causing any form of collapse to the formation for this condition to focusing on ECD and rheological properties (Stephen and Samuel, 2008). Oil well drilling paste compositions are typically used for sealing subterranean zone at High Temperature and High Pressure (HTHP) such as the annular space in oil well between the surrounding formation and casing (Shahriar and Nehdi, 2011). The slurry blend consists of cement class $G$ with additives and water. The productivity of an oil well is significantly affected by the quality of drilling pasting between the well casing and the surrounding strata (Teodoriu et al., 2008). The drilling slurry flow ability and stability are major requirements for successful oil well cementing (Kulakofsky and Vargo, 2005) because the drilling paste is the most active component of the slurry and usually has the greatest unit cost. Its selection and proper use are important in obtaining an effective, for long term integrity of the well (Williams et al., 1999). Portland pastes can be used for cementing around the casing of oil and gas wells having deeper depth wells usually require special oil well drilling pastes (Teodoriu et al., 2008). There are currently eight classes of API Portland drilling pastes designated A through $\mathrm{H}$ that are arranged according to the depths to which they are placed at pressure and temperature to which they are exposed (Harris and Service, 1991). In oil well drilling industry class $\mathrm{G}$ and $\mathrm{H}$ type well drilling pastes are well known for deep wells; because in addition other than calcium sulfate and water both shall be inter-ground or blended to the clinker during manufacturing of this oil well paste. Therefore with addition of ample quantity of additives such as retarders and dispersants can change their setting time to the cover wide range of well depths, pressure and temperature (Kulakofsky and Vargo, 2005). In this study, the silica fume used as extender, as it is function to reducing slurry density also light slurry is used to control hydrostatic pressure during cementing operation. This slurry has greater strength to use in weak and unconsolidated formation.

Mixing energy: The paste slurry is a mixture of bentonite, water and additives (Stephen and Samuel, 2008). The mixing process is exothermic and the energy required to this called is 
mixing energy.

The mixing energy equation is given as Williams et al. (1999) and Rehman Memon and Talib Shuker (2013):

$$
\mathrm{E} / \mathrm{M}=\mathrm{k} \omega^{2} \mathrm{t} / \mathrm{V}
$$

Where,

$\begin{array}{ll}\text { E } & \text { Mixing energy }(\mathrm{KJ}) \\ \mathrm{M} & \text { Mass of slurry }(\mathrm{kg}) \\ \mathrm{K} & 6.1 * 10^{-8} \mathrm{~m}^{5} / \mathrm{s}(\text { constant found experimentally) } \\ \omega & \text { Rotational speed (radians } / \mathrm{s}) \mathrm{t} \\ \mathrm{t} & \text { Mixing time }(\mathrm{sec}) \\ \mathrm{V} & \text { Slurry volume }\left(\mathrm{m}^{3}\right)\end{array}$

The prepared cement slurry is dispatch to Viscometer for measuring rheological properties. The silica fume is obtained from WR Grace Malaysia which a global specialty in chemicals and drilling fluid materials. Standard of well drilling fluid test: American Petroleum Institute (API) has presented "Recommended practice for testing well drilling fluid $\mathrm{s}$ (American Petroleum Institute, 2005). The standard has been followed which is used worldwide. These tests are advise and very helpful to drilling personnel for determine a given drilling fluid composition will be feasible for well conditions according to API-10B (American Petroleum Institute, 2005).

Experimental procedure: Drilling fluid slurry is prepared according to API-10B (American Petroleum Institute, 2005). The mixing method strongly influences on slurry and set cement properties. Cement additives can be wet blended in cement slurry. When additives are mixed in water prior into cement, it is called wet blending.

Electronic balance: This is used for weighting dry cement, distilled water and additives, to use for preparation of drilling fluid slurry.

Electronic standard 7000 constant speed mixer: Measure cement and additive prepared in lab using the standard 7000 Constant Speed Mixers provide all the necessary functions to mix drilling slurries according to API and ISO specifications and recommended practices. Normally $600 \mathrm{~mL}$ of slurry are prepared. Slurry is mixes for $70 \mathrm{sec}$ the mixer is operated at 4000 RPM during first $15 \mathrm{sec}$ which the dry cement is added to water this is followed by $35 \mathrm{sec}$ at that condition set mixer at $12000 \mathrm{RPM}$ followed at $70 \mathrm{sec}$.

Rheology measurement: The prepared drilling slurry is placed into sample cup i.e., Bob having capacity of drilling fluid is $42 \mathrm{~mL}$ slurry different Bob having different capacity for drilling slurry's high performance advance pressurized viscometer model 1100 with ORCADA software is used for measuring thermal and rheological properties of drilling slurry's. According to API recommended practice 10B viscometer is used for oil well drilling fluid testing materials having wide range of temperatures. Where the viscosity is determined, the dial readings at various rotational speeds are giving the slurry behavior at different condition. In this study, the temperature is set at above $120^{\circ} \mathrm{C}$ the viscometer heat bath help to simulate down whole condition. After heat conditioning, the viscometer starts to take the dial reading at different RPMs to measure thermo electrical and also, the rheological parameter at down whole condition.

\section{Materials and Method}

\subsection{Properties of Ferric Oxide}

The ferric oxide nanoparticles, a common ingredient has a huge variety of applications. This topic is proven that, the application of $\mathrm{Fe}_{2} \mathrm{O}_{3}$ nano particles in low dosage is not toxic. So, this type of metal oxide is chosen as additive.

\subsection{Method of Preparation of Ferric Oxide Nanoparticle}

The nano fluids that are used in this experimental work are prepared in two steps. At the first, the amount of $1.16 \mathrm{~g}$ of ferric oxide in powder form is dissolved in de-ionized water contains $0.38 \mathrm{~g}$ of citric acid crystals. Then ferric hydroxide is added gradually (till obtaining $\mathrm{pH}=7$ ) into the mixture and is homogenized effectively in magnetic stirrer simultaneously. To produce the powder form of ferric oxide, the mixture is heated for $1.5 \mathrm{hr}$ at $265^{\circ} \mathrm{C}$ and then to $522^{\circ} \mathrm{C}$ for $90 \mathrm{~min}$ to change the color of powder into bright brown. Nano particles diameter is in the range of 75-89 $\mathrm{nm}$ and morphology of particles are characterized with SEM and TEM images.

\section{Results and Discussion}

The experimental results are shown in this section of article. Important thermo electrical and rheological properties of slurry mud as a non-Newtonian fluid such as; electrical conductivity, themal conductivity, overall heat transfer coefficient, yield stress, apparent viscosity and plastic viscosity are studied. The effect of amounts of nano particle, temperature and amounts of shear rate on the above parameters are reported in the following Figures.

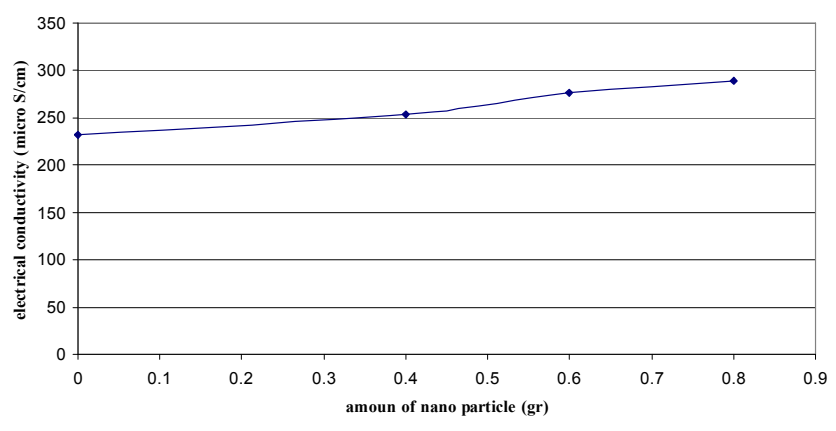

Figure 1. The effect of injected nano particle mass on the electrical conductivity.

The Figure 1 shows the relation between the amount of added ferric oxide nano particles and the electrical conductivity. The unit of electrical conductivity is reported as micro Siemens per centimeter. The electrical conductivity is increased when the percentage of ferric oxide is increasing. Experimental results show the electrical conductivity can promote from 240 to 290 , approximately. The relation between the amount of ferric nano particle and 
electrical conductivity is direct and this is related to the metal properties of ferric nano oxide as metal oxide nano particles.

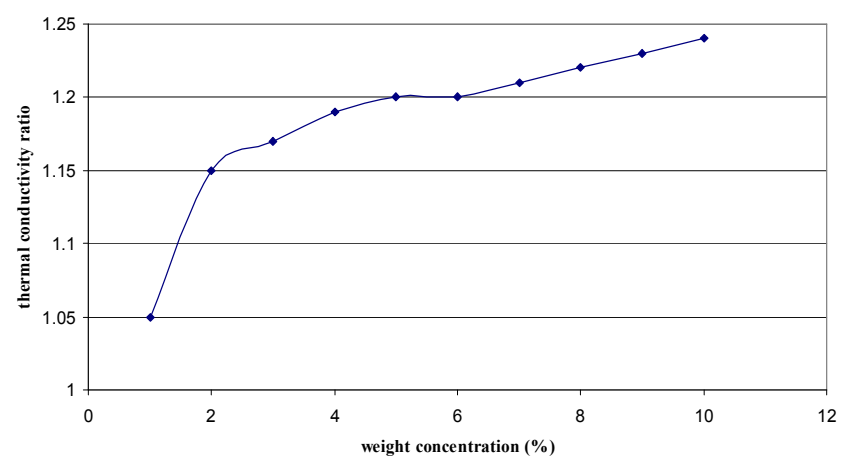

Figure 2. Relation between weight concentration of nano particle and thermal conductivity ratio.

The amount of added ferric nano particles on the thermal conductivity ratio is evaluated in the Figure 2. The obtained results show the thermal conductivity ratio which is defined as thermal conductivity of nano drilling fluid per thermal conductivity of simple drilling fluid is increasing with the increasing the weight percentage of ferric oxide nano particles. The nature of nano ferric oxide can promote the ability of drilling fluid in the transfer of heat. As we know, the ability of drilling fluid in the transfer of heat is a basic role of this fluid. So, the nano drilling fluid can role this character better than the simple drilling fluid.

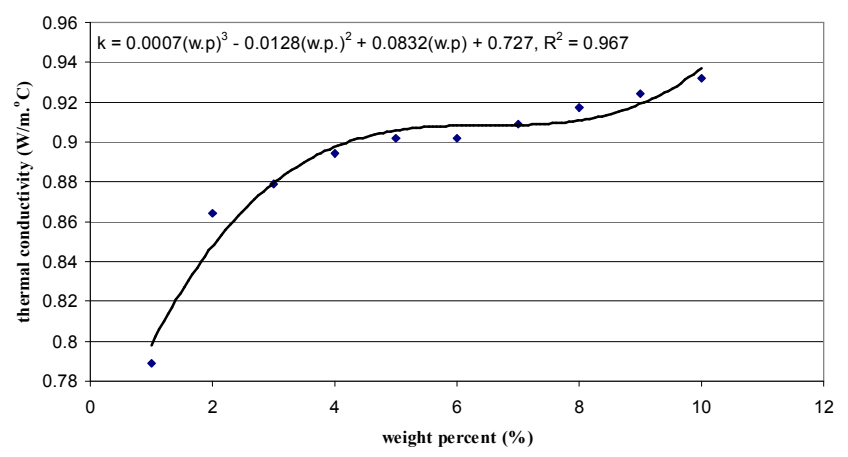

Figure 3. The relation between the weight percent and thermal conductivity values.

The effect of ferric nano particles are evaluated in the Figure 3. The Figure 3 proves that the ferric oxide nano particle as metal oxide nano particle can increase the thermal conductivity values, severely. Results show the behavior of nano drilling fluid in the conduction mechanism can followed by polynomial with order 3 th. The slope of this poly nomial is positive and the regression of this curve is 0.967 . Therefore, the defined polynomial can be valid able to predict the thermal conductivity of nano drilling fluid in the different amounts of ferric oxide nano particles. The equation 2 can be illustrated the relationship.

$$
\left.\left.\mathrm{K}=0.0007 \text { (w.p. })^{3}-0.0128 \text { (w.p. }\right)^{2}+0.0832 \text { (w.p. }\right)+0.727
$$

\section{Conclusions}

The effects of nano particles on the thermo electrical and rheological properties of drilling fluid are investigated in this research. Experimental results show the electrical conductivity can promote from 240 to 290, approximately. The relation between the amount of ferric nano particle and electrical conductivity is direct and this is related to the metal properties of ferric nano oxide as metal oxide nano particles. The obtained results show the thermal conductivity ratio which is defined as thermal conductivity of nano drilling fluid per thermal conductivity of simple drilling fluid is increasing with the increasing the weight percentage of ferric oxide nano particles. The nature of nano ferric oxide can promote the ability of drilling fluid in the transfer of heat. The experimental results prove that the ferric oxide nano particle as metal oxide nano particle can increase the thermal conductivity values, severely. Results show the behavior of nano drilling fluid in the conduction mechanism can followed by polynomial with order 3 th.

\section{References}

[1] American Petroleum Institute, 2005. Recommended Practice for Testing Well Cements. API Publishing Services, Washington, D. C., pp: 171.

[2] Banfill, D. and P. F. G. Kitching, 1991. The Yield Stress of Oilwell Cement Slurries. In: Rheology of Fresh Cement and Concrete.

[3] Bannister, C. E., 1980. Rheological evaluation of cement slurries: Methods and models. Proceeding of the SPE Annual Technical Conference and Exhibition, September 21-24, Dallas, Texas.

[4] Boukhelifa, L., N. Moroni, E. Spa, S. G. James, S. L. R. Delage, M. J. Thiercelin, G. Lemaire, I. Natl and A. Insa, 2005. Evaluation of cement systems for oil- and gas-well zonal isolation in a full-scale annular geometry. SPE Drill. Comp., 20 (1): 44-53.

[5] Frittella, B. S. F., B. J. Services and M. Babbo, 2009. Best practices and lessons learned from 15 years of experience of cementing hpht wells in Italy. Proceeding of the SPE/IADC Middle East Drilling Technology Conference and Exhibition, October 26-28, Manama, Bahrain.

[6] Grinrod, M. and B. Vassoy, 1988. Development and use of a Gas-tight cement. Proceeding of the IADC/SPE Paper No. 17258 , Presented at the 1988 IADC/SPE Drilling Conference held in Dallas, Texas, February.

[7] Guillot, D., 2006. Rheology of Well Cement Slurries. In: Nelson, E. B. and D. Guillot (Eds.), Well Cementing. Texas, Schlumberger, pp: 93-142.

[8] Harris, K. L. and H. Service, 1991. New lightweight technology for the primary cementing of oilfield casings in cold environments. Proceeding of 3th International Arctic Technology Conference, May 29-31, Anchorage, Alaska.

[9] Hodne, H., 2007. Rheological performance of cementitious materials used in well cementing. Ph.D. Thesis. 
[10] Kulakofsky, D. and R. Vargo, 2005. New technology for the delivery of beaded lightweight cements. Proceeding of the SPE Annual Technical Conference and Exhibition, October 912, Dallas, Texas.

[11] Labibzadeh, M., B. Zahabizadeh and A. Khajehdezfuly, 2010. Early-age compressive strength assessment of oil well class $\mathrm{G}$ cement due to borehole pressure and temperature changes. Science, 6 (7): 38-47.

[12] Mehta, P. K. and O. E. Gjorve, 1982. Properties of portland cement concrete containg fly ash and condensed silica fume. Cem. Concr. Res., 12 (5): 587-595.

[13] Miranda, C. R., R. D. Petrobras, F. Toledo and E. M. R. Fairbairn, 2010. New design of high-performance cement systems for zonal isolation: Influence on porosity, rheological parameters and chemical and mechanical resistance. Proceeding of the SPE Latin American and Caribbean Petroleum Engineering Conference, December 1-3, Lima, Peru.

[14] Mirza, J., M. Mirza, V. Roy and K. Saleh, 2002. Basic rheological and mechanical properties of high-volume fly ash grouts. Construct. Build. Mater., 16 (6): 353-363.
[15] Mueller, D. T., R. L. D. Iii, T. Western and N. America, 1991. The versatility of silica fume as an oilwell cement admixture. Proceeding of the SPE Production Operations Symposium, April 7-9, Oklahoma City, Oklahoma, pp: 529-536.

[16] Nediljka, G. M., M. Davorin and K. Gracijan, 1994. Cement slurries for geothermal wells cementing. Rudarsko-GeološkoNaftni Zbornik, 6 (1): 127-134.

[17] Shadizadeh, S. R., M. Kholghi and M. H. S. Kassaei, 2010. Experimental investigation of silica fume as a cement extender for liner cementing in iranian oil. Gas Wells, 7 (1).

[18] Shahriar, A. and M. L. Nehdi, 2011. Anjuman Shahriar Investigation on Rheology of Oil Well Cement Slurries.

[19] Shahriar, A. and M. L. Nehdi, 2012. Optimization of rheological properties of oil well cement slurriesusing experimental design. Mater. Struct., 45 (9): 1403-1423.

[20] Khalil Rehman Memon, Muhannad Talib Shuker, Investigating Rheological Properties of High Performance Cement System for Oil Wells, Research Journal of Applied Sciences, Engineering and Technology 6 (20): 3865-3870, 2013. 